\title{
Cómo entender y tratar el narcisismo con terapia EMDR
}

\author{
Dolores Mosquera \\ INTRA-TP, Instituto para el Estudio del Trauma y los Trastornos de la Personalidad, A Coruña, España \\ Jim Knipe \\ Longmont, Colorado
}

\begin{abstract}
El trastorno narcisista de la personalidad y los rasgos narcisistas están asociados con conductas egoístas y falta de empatía hacia los demás. Los pacientes con alguna de estas presentaciones iniciales en terapia muestran un perfil centrado en sí mismos y una falta de empatía o preocupación por el sufrimiento que pueden causar a otras personas, pero esto es sólo parte de la historia. En ocasiones, la falta de empatía y el egoísmo son sólo una defensa. Para entender completamente este problema, también es necesario ser consciente de los problemas subyacentes de autodefinición que llevan a las manifestaciones conductuales del narcisismo. Como en cualquier problema psicológico, el tratamiento con la terapia de desensibilización y reprocesamiento por movimientos oculares exige comprender la manera en la que las primeras experiencias dan lugar a los futuros síntomas. Es fundamental comprender el recorrido desde las experiencias tempranas a las características narcisistas (incluidas las presentaciones encubiertas) para poder realizar una buena conceptualización del caso, así como entender las estructuras mentales de defensa que impiden acceder a las experiencias adversas nucleares que subyacen a los síntomas.
\end{abstract}

Palabras clave: narcisismo; desensibilización y reprocesamiento por movimientos oculares (EMDR); trastorno narcisista de la personalidad; trauma; procesamiento adaptativo de la información.

$\mathbf{L}$ es habitual que los terapeutas estemos familiarizados con las cualidades obvias del narcisismo, como la grandiosidad, la explotación de los demás, la arrogancia, los problemas interpersonales y la ira, pero las presentaciones encubiertas pueden pasar desapercibidas y, por tanto, no ser tratadas. El objetivo de este artículo es enfocarnos en los distintos tipos de presentación del narcisismo, la manera en que puede conceptualizarse desde el modelo de procesamiento adaptativo de información (PAI) y tratarse con terapia de sensibilización y reprocesamiento por movimientos oculares (EMDR) (Shapiro, 2001).

\section{El concepto de narcisismo}

Los individuos narcisistas pueden definirse como personas que están excesivamente preocupadas con temas de valía personal, poder, prestigio y vanidad
(Millon, 1996). Podemos definir el narcisismo desde tres perspectivas diferentes: las conductas del individuo narcisista, los patrones de "relaciones objetales" del narcisismo (es decir, las maneras en las que una persona piensa sobre las relaciones con los demás) y el aspecto fenomenológico del narcisismo (es decir, cómo se siente uno siendo un narcisista). Se han definido los distintos aspectos conductuales de la estructura de la personalidad narcisista en términos de la "tríada oscura», conjuntos de rasgos que están relacionados y a menudo coexisten, pero conceptualmente están separados: (a) narcisismo (expectativa de privilegios, creerse superior a los demás, conductas dominantes), (b) maquiavelismo (encanto social superficial, manipulación) y (c) psicopatía (actitudes sociales crueles, impulsividad, antagonismo interpersonal; Jonason, Lyons y Bethell, 2014; Kowalski, 2001).

This article originally appeared as Mosquera, D. \& Knipe, J. (2015). Understanding and Treating Narcissism. Journal of EMDR Practice and Research, 9(1), 46-63. Translated by Miriam Ramos Morrison. 
Para los terapeutas (de EMDR) que tratan personas con características narcisistas dentro de un modelo PAI, el aspecto fenomenológico es particularmente importante porque el enfoque PAI hace diana específicamente sobre los sentimientos no deseados por el paciente y las experiencias subjetivas de infelicidad. Fenomenológicamente, las personas narcisistas pueden describirse como excesivamente centradas y protectoras de una imagen exageradamente valorada de sí mismos. Esta imagen a menudo está idealizada, en el sentido de que el autoconcepto de la persona está distorsionado, con una excesiva autovaloración, actitudes de ser especial, superioridad, expectativas de privilegios e inmunidad a algunas de las reglas de conducta adecuada.

Como terapeutas de EMDR, es importante darnos cuenta de que este tipo de autoimagen exageradamente positiva y distorsionada, basada en gran medida en experiencias previas de la vida, es susceptible de utilizarse como blanco y resolverse a través de intervenciones relacionadas con el EMDR. Al igual que se pueden utilizar con eficacia los procedimientos de la terapia EMDR para hacer blanco sobre emociones incómodas y resolverlas, o sobre una autodefinición negativa exagerada, del mismo modo también se pueden utilizar como blancos los recuerdos centrales que generan un sentido de uno mismo exageradamente positivo (Knipe, 2014) para hacer que esos recuerdos lleguen a una resolución adaptativa, dando lugar a una autovaloración más realista.

Para muchos individuos, las conductas narcisistas parecen ser la fachada de un cuadro más complejo. Diversas teorías (Gabbard, 1989; O. Kernberg, 1975; Millon, 1990) postulan que la persona necesita actuar como si fuera superior o mejor que los demás para compensar su oculta autodefinición interna de ser un fracaso o ser mediocre.

Junto con estas características personales del cuadro clínico, existe a menudo una falta de empatía por las emociones y deseos de los demás (American Psychiatric Association [APA], 2013), que se ha propuesto nace de una falta de "percepción del objeto", esto es, no percibir completamente la realidad de que los demás tienen necesidades, percepciones, actitudes, etc. independientes (Masterson, 1981). Con frecuencia, los narcisistas no se relacionan realmente con los demás como seres humanos diferentes y separados, sino simplemente como «objetos» a utilizar para lograr cubrir una necesidad personal (Millon, 1996). Suponemos que esta deficiencia en la empatía es una parte del daño causado por la frustración temprana de los «sistemas de acción» de apego innatos (van der Hart, Nijenhuis y Steele, 2006) y lo vemos como frustración relacionada con los primeros intentos de conectar empáticamente con los demás, durante la más temprana infancia, o una simple imitación de lo que aprendieron de sus cuidadores (Mosquera, 2012, 2013).

Por último, la experiencia de un narcisista puede tener momentos de placer eufórico cuando logra una "victoria», lo cual cree que prueba su superioridad. Sin embargo, en nuestra práctica clínica hemos notado que esta manera de lograr objetivos, aun cuando tenga éxito, no tiende a calar hondo. Ser admirado como «el victorioso» satisface menos que ser amado de verdad. En el tratamiento de un paciente con rasgos narcisistas, es necesario tener en cuenta estos tres puntos de vista, tal y como se describirá a continuación.

\section{El desarrollo del narcisismo}

Los estudios clínicos han indicado que las experiencias infantiles de abuso físico, abuso sexual, abuso emocional, negligencia física y negligencia emocional son frecuentes en pacientes con trastornos de personalidad (Battle et al., 2004; Bierer et al., 2003; D. M. Johnson, Shehan y Chard, 2004; Luntz y Widom, 1994; Rettew et al., 2003; Yen et al., 2002; Zanarini et al., 2000; Zanarini, Gunderson, Marino, Schwartz y Frankenburg, 1989; Zanarini et al., 1997; Zanarini et al., 2002). Los estudios con métodos de muestreo por conveniencia (Gibb, Wheeler, Alloy y Abramson, 2001; Grover et al., 2007; Tyrka, Wyche, Kelly, Price y Carpenter, 2009) y muestras comunitarias pequeñas (J. G. Johnson, Cohen, Brown, Smailes y Bernstein, 1999; J. G. Johnson, Cohen, Chen, Kasen y Brook, 2006; J. G. Johnson, Smailes, Cohen, Brown y Bernstein, 2000) también han respaldado esta asociación, pero sigue sin estar claro si existe la relación entre trastornos de personalidad y adversidades en la infancia en muestras representativas de población general (Afifi et al., 2011). La investigación que se cita ha estudiado el desarrollo del trastorno narcisista de personalidad, pero los autores asumen que las conclusiones de esta investigación también pertenecen, tal vez en menor medida, a otros individuos que no son diagnosticados con trastorno narcisista de la personalidad pero tienen trastornos con rasgos narcisistas relevantes.

Cohen et al. (2014) indicaron que el maltrato infantil, incluido el abuso emocional, físico y sexual, y la negligencia, representan un potente factor de riesgo ambiental para la patología de la personalidad. Estos autores señalan que una importante cantidad de estudios enlazan el maltrato infantil con resultados adversos en la edad adulta, incluida la patología de la personalidad (Collishaw et al., 2007; Lobbestael, 
Arntz y Berstein, 2010). Sin embargo, no está claro si los distintos tipos de maltrato infantil predicen tipos concretos de patología de la personalidad.

Los estudios empíricos y metaanalíticos sugieren que los rasgos de personalidad narcisista y egocéntrica han ido en aumento en el mundo entero en las últimas décadas (Cai, Kwan y Sedikides, 2012; Twenge, Konrath, Foster, Campbell y Bushman, 2008; aunque también véase Trzesniewski, Donnellan y Robins, 2008). La "epidemia narcisista» se puede observar en el aumento de las puntuaciones del inventario de personalidad narcisista (Twenge et al., 2008), en el contenido de las letras de las canciones pop (DeWall, Pond, Campbell y Twenge, 2011), en el uso egocéntrico de palabras y frases en libros (Twenge, Campbell y Gentile, 2012) y en el descenso de la empatía disposicional (Konrath, O’Brien, \& Hsing, 2011). El narcisismo se ha asociado a las características de una cultura (Foster, Campbell y Twenge, 2003) y el cambio en las disposiciones narcisistas podría tener relación directa con el cambio cultural (Cai et al., 2012), que a menudo se alimenta del desarrollo económico (Hamamura, 2012). Pese a la explosión de estudios sobre las diferencias generacionales y culturales en el narcisismo, las causas proximales de estas diferencias siguen sin aclararse (Lyons, Morgan, Thomas y Al Hashmi, 2013).

\section{Narcisismo y procesamiento adaptativo de la información/EMDR y los modelos psicoanalíticos de psicoterapia}

Un abordaje EMDR del tratamiento del narcisismo comienza con la suposición, una hipótesis, de que el narcisismo se basa en experiencias difíciles y dañinas en los comienzos de la vida. Estas pueden ser acontecimientos traumáticos específicos (Afifi et al., 2011) o la situación más frecuente de "traumas por omisión», situación en la que el niño se siente repetidamente frustrado en relación a sus necesidades de apego y nutrición emocional (Cohen et al., 2014). Estamos asumiendo que, en el individuo adulto con narcisismo han influido ambos tipos de trauma, no sólo a la hora de generar recuerdos almacenados de manera disfuncional de acontecimientos perturbadores, sino también otros elementos almacenados disfuncionalmente (DSE, por sus siglas en inglés; Gonzalez y Mosquera, 2012) con base traumática, tales como defensas psicológicas y a menudo disociación (es decir, falta de acceso consciente y completo entre estados del yo / redes de memoria que funcionan por separado).

La base teórica de nuestro trabajo es una integración del modelo PAI de EMDR (Shapiro, 2001) y una perspectiva psicoanalítica (O. Kernberg, 1975; Kohut, 1971; Masterson, 1981; Millon, 1996). Estos modelos difieren de las siguientes maneras: La teoría psicoanalítica contiene subconsciente, proyecciones y defensas. Se entiende que las defensas, cumplen una función protectora y se aprenden en la infancia temprana como manera de compensar los fracasos o falta de sintonía. El modelo de terapia PAI, por el contrario, ve la base de la psicopatología en las redes de memoria disfuncionales y postula que algunas redes se mantienen fuera de la conciencia porque su activación es potencialmente abrumadora y amenazante. Estos modelos de terapia comparten la creencia de que las experiencias infantiles puede relacionarse con características específicas de la psicopatología en adultos.

Ambas teorías consideran los rasgos narcisistas como el resultado final de un entorno negligente, abuso crónico u otras experiencias adversas (Afifi et al., 2011), pero estas características también pueden estar relacionadas con una valoración excesiva poco realista y exceso de atención (Jonason et al., 2014; Kowalski, 2001; Millon, 1990; Stone, 1993). También se ha encontrado que toda una variedad de trastornos de apego con cuidadores primarios da lugar a falta de empatía y egocentrismo (Bennett, 2006; Campbell y Foster, 2002; Cramer, 2010; P. F. Kernberg, 1998; Lyons et al., 2013). Debido a que el narcisismo funciona a menudo como defensa psicológica (P. F. Kernberg, 1998; Knipe, 1998; Mosquera, 2008), es decir, como manera de evitar la toma de conciencia o la aparición de perturbación emocional, puede haber una variedad de circunstancias difíciles de la vida que lleven al desarrollo de esta defensa.

En este artículo, proponemos la hipótesis de que con una preparación adecuada y sintonía compasiva adecuada por parte del terapeuta, tanto los recuerdos disfuncionales como los otros DSE pueden llevarse a una resolución adaptativa mediante determinadas intervenciones PAI que implican tandas enfocadas de estimulación bilateral. Este artículo proporciona unas pautas generales y no pretende minimizar la enorme complejidad y variedad de las estructuras de personalidad narcisista que pueden subyacer a la presentación conductual superficial.

\section{Narcisismo y trauma temprano}

A menudo, los terapeutas suelen ser conscientes del narcisismo principalmente a causa del daño o el dolor perpetrado por individuos narcisistas a los pacientes que llegan a terapia. Con los pacientes que han sido dañados de esta manera, es necesario enfocarse en cómo el maltrato ha generado sentimientos 
y una autodefinición de victimización indefensa. Pero cuando el paciente es un individuo con rasgos narcisistas, es necesario una perspectiva diferente, una que tome en consideración la experiencia que tiene ese individuo de sí mismo y los demás y también una conciencia por parte del terapeuta de cómo un estilo narcisista puede impedir que esa persona disfrute normalmente de las experiencias satisfactorias de la vida, logre objetivos terapéuticos y establezca relaciones sanas con los demás.

Podríamos pensar en el narcisismo como problema emocional que a menudo se esconde muy bien de los demás y sólo se hace evidente en sus efectos dañinos sobre la persona o personas en relación con el individuo narcisista. Las personas que son narcisistas vuelcan mucha energía no sólo en adaptarse, sino en parecer ejemplares, mejores que los demás. La mayoría de las personas se angustiarían hasta cierto punto si pareciesen torpes a ojos de otras personas, pero para la persona narcisista es probable que esta angustia se amplificase porque significa la pérdida de una defensa importante frente a sentimientos perturbadores no resueltos. Por ejemplo, si el individuo narcisista aprende de niño que «debo parecer inteligente e impresionar a otras personas en todo momento para ganarme el amor de mis padres», entonces siquiera un pequeño lapso en parecer inteligente podría suscitar todas las emociones de abandono emocional que ocurrieron en la relación disfuncional original con los padres. Por tanto, el individuo ha de impresionar en todo momento para mantener esta defensa y evitar una reactivación de estas emociones infantiles tempranas de abandono y de no merecer amor (P. F. Kernberg, 1998). Por estos motivos, es más que probable que el tratamiento del narcisismo con EMDR implicará en última instancia hacer blanco sobre traumas tempranos de omisión, en los que la indiferencia de los padres hacia el niño podría influir para que el niño se volviese casi una réplica perfectamente exacta de lo que los padres necesitan. De este modo, la necesidad de conexión del niño puede satisfacerse parcialmente (Cramer, 2010; Winnicott, 1965).

Esto no quiere decir que la causa del narcisismo sean exclusivamente las experiencias tempranas difíciles. El narcisismo es un rasgo de personalidad relacionado parcialmente con factores genéticos (Livesley, Jang, Jackson y Vernon, 1993). Sin embargo, una hipótesis fundamental del enfoque PAI que aquí se presenta, así como en otros trabajos (Stone, 1993), es que las experiencias adversas tempranas y las perturbaciones del apego contribuyen sustancialmente al problema del narcisismo en el adulto, especialmente en relación a la falta de empatía y el egocentrismo.
Egocentrismo patológico frente a narcisismo normal en la infancia

Los niños con una patología narcisista muestran un tipo de egocentrismo diferente al narcisismo normal de la infancia (P. F. Kernberg, Weiner y Bardenstein, 2000). En el narcisismo normal, las necesidades de dependencia y admiración del niño se cubren al recibir una atención adecuada a su edad; son capaces de reconocer el cariño con reciprocidad y gratitud (P. F. Kernberg et al., 2000) y aprender fácilmente la satisfacción de la empatía y la implicación con los demás. El desarrollo normal puede alterarse cuando existen perturbaciones en el apego (Bennett, 2006) y diversas experiencias adversas (Afifi et al., 2011; Lyons et al., 2013), como no ser visto por los cuidadores con ojos tanto realistas como amorosos (Knipe, 2007; Millon, 1990; Mosquera y Gonzalez, 2011; Stone, 1993). El camino desde las experiencias tempranas hasta el desarrollo de rasgos narcisistas puede ser diverso y puede ocurrir de maneras diferentes en distintos pacientes. Desde nuestra perspectiva, el falso yo narcisista se entiende como una defensa frente a los recuerdos traumáticos, normalmente traumas de omisión y falta de implicación, aunque algunas veces son traumas de perpertración.

\section{Búsqueda desesperada de reconocimiento positivo}

Bajo la superficie de la presentación narcisista puede existir una amplia variedad de experiencias traumáticas. Los autores han observado que el patrón para esto se establece en los primeros años de vida, generalmente por la manera en que distintos cuidadores tratan al niño, o las distintas maneras en que el mismo cuidador trata al niño, o ambas. Un niño puede adquirir diferentes autoconceptos de diferentes cuidadores; por ejemplo, cuando un cuidador idealiza a un niño y el otro le critica mucho. Esto puede ocurrir cuando la madre le da una atención excesiva y el padre es muy crítico, o viceversa, y los padres se polarizan en sus respuestas ante el niño. Esto es muy confuso para el niño y, en estos casos, los padres utilizan a menudo al niño como campo de batalla para sus propios conflictos no resueltos. Puede establecerse un patrón de dos estados del yo separados cuando el niño no obtiene, de ninguno de los padres, el suficiente reconocimiento y reflejo de su propia experiencia interna y busca desesperadamente una manera de recibir reconocimiento positivo de uno o ambos padres. Buscar la perfección a ojos de los demás no es realmente satisfactorio en términos de conexión pero puede convertirse en una «acción sustitutiva» (van der Hart et al., 2006), 
una conducta con una motivación muy alta, con el objetivo de obtener simplemente una sensación de conexión.

\section{Cómo se aprende el valor de la superioridad}

Los padres del niño pueden tener características narcisistas, ocultas de las personas externas a la familia, pero conocidas y modeladas por el niño (Mosquera, 2012). El entorno familiar es "normal» en la superficie, pero a nivel más profundo, puede haber insuficiente sintonía, conexión, afecto y reconocimiento de las necesidades del niño (Afifi et al., 2011; Bennett, 2006; Cramer, 2010; P. F. Kernberg, 1998). Hemos visto pacientes que han crecido en estas circunstancias y han aprendido que ser especial y superior era una forma de ganar aceptación y, por tanto, fortalecer la frágil conexión con los cuidadores. Los aspectos de este niño que "no eran especiales» tenían que esconderse, tal vez incluso excluirse de la conciencia del niño. Un paciente indicó que, con siete años, se sentía muy conectado de manera positiva a sus padres cuando entraba en sus fiestas y se paseaba entre los invitados dándoles la mano con firmeza e intentando decir cosas ingeniosas a cada uno de ellos. Cuando, en el tratamiento terapéutico, se hizo blanco sobre este recuerdo inicialmente positivo, sus pensamientos rápidamente fueron a: "Tenía que impresionar a todo el mundo, ¡pero no veía la hora de salir de allí!» En otras palabras, su emoción positiva no era profunda y era una una fina capa de las emociones más básicas de falta de adecuación y conexión con sus egocéntricos padres. En su vida adulta, este paciente había cultivado «un millón de amigos» pero se sentía frustrado por la falta de verdadera intimidad con ninguno de ellos. Para él fue útil ver los orígenes de esta manera particular de relacionarse con los demás, para entonces poder empezar a aprender cómo lograr una cercanía más real y satisfactoria.

Incluso cuando los cuidadores del niño no son abiertamente narcisistas, puede que utilicen al niño para compensar sus deseos frustrados y/o creencias de inferioridad y falta de valía (P. F. Kernberg, 1998; Millon, 1990; Segrin, Woszidlo, Givertz y Montgomery, 2013; Stone, 1993). Se piensa que los niños que crecen en una familia que no es lo suficientemente cariñosa tenderán a cubrir las necesidades de los padres como manera de mantener una conexión necesaria con esos cuidadores. Hemos observado que cuando el progenitor tiene una personalidad narcisista, incluso de manera oculta, el principal modo de conexión con los padres puede ser que el niño se vuelva el «objeto narcisista» del progenitor, un niño que parece ser ideal.
Se establece por tanto una conexión progenitor-hijo, pero el precio que ha de pagar el hijo es la negación de sus necesidades y cualidades intrínsecas particulares que los padres no pueden reconocer o tolerar. Esta situación puede exacerbarse si el niño se vuelve el foco de alabanzas y atenciones excesivas y poco realistas y de un exceso de expectativas positivas (tanto si el niño tiene un talento inusual como si no), lo que puede dar lugar a lo que Tartakoff (1966) llamó el complejo de Premio Nobel. Para el niño puede ser emocionante plantearse el sentimiento de superioridad y el estar destinado a la grandeza, pero también puede ser una fuente de una enorme presión emocional y estar fuera de sintonía con las habilidades o conductas reales del niño.

\section{Desarrollo de una prepotencia grandiosa}

Algunos pacientes con tendencias narcisistas crecen con un sentido distorsionado de sí mismos, que refleja distorsiones en el trato que han recibido de sus cuidadores. En algunos casos, hemos visto padres «aparentemente comprensivos» que promueven actitudes de sentirse con derecho a recibir privilegios. Estos padres no han fomentado actitudes de humildad y autorreflexión apropiadas, esto es, aprender de los errores mientras se mantiene una sensación de valía personal.

Tal y como indica Stone (1993), el narcisismo puede provenir tanto de «demasiado» (sobreprotección, exceso de alabanzas) como de "no lo suficiente» (entornos gravemente traumatizantes o negligentes) y ambas condiciones pueden ocurrir en la misma familia. Stone usa la palabra compensatorio para describir esta estructura de personalidad porque la sensación de ser especial funciona para compensar parcialmente la indiferencia y la negligencia de los padres. En esta situación, el niño puede desarrollar un deseo exagerado de "grandiosidad» como manera de reforzar una sensación de valía personal en ausencia de alabanzas parentales normales y más realistas. En este caso, la experiencia interna y la conducta externa del niño desatendido pueden expresar dos autoconceptos muy diferentes: una sensación hacia el exterior de ser especial que es compensatoria y cubre una sensación interna de falta de valía (Stone, 1993). Se piensa que, en este contexto, los rasgos narcisistas funcionan como defensas que previenen la aparición en la conciencia de emociones de devaluación personal (Nathanson, 1992), que se pueden considerar como un síntoma postraumático con origen en el trauma de un abandono emocional repetido. Estas defensas son con frecuencia complejas y elaboradas (P. F. Kernberg, 1998). 
Desarrollo de una gran vulnerabilidad a los juicios negativos de los demás

Aunque la prepotencia grandiosa es fundamental en el trastorno narcisista de la personalidad, la vulnerabilidad de la autoestima es una característica asociada (P. F. Kernberg, 1998; P. F. Kernberg et al., 2000; Millon, 1990). Dado que la imagen idealizada que el paciente narcisista tiene de sí mismo es una distorsión de lo que realmente es cierto, y él o ella está extremadamente interesado en mantener esta imagen, la percepción de la realidad en sí puede ser muy amenazante, y otras personas que dicen la verdad libremente pueden verse como amenazas. Volkan (1973) ha descrito diversas maniobras defensivas (p. ej., culpar, devaluar) utilizadas por los individuos narcisistas para proteger su identidad grandiosa del ataque de la realidad. Por tanto, se puede desarrollar una estructura de personalidad narcisista como manera de conectar con los cuidadores, como forma de defenderse frente a sentimientos postraumáticos de abandono y como internalización de cuidadores narcisistas inadecuados.

El grandioso sentido de identidad del niño puede entenderse como el resultado de la fusión de los aspectos positivos del yo real, el yo ideal y los modelos ideales, junto a la eliminación de cualquier cosa que sea incompatible (es decir, parcial o completamente disociada), con lo cual lo que queda es una autoimagen exagerada en cuanto a lo positivo (P. F. Kernberg et al., 2000). Una persona con rasgos narcisistas debe negar todo lo que no encaje con su sentido grandioso de identidad, lo cual significa percibir a los demás (y a sí mismo) de manera distorsionada. Otras personas, así como algunas partes del yo, se devalúan y separan, dando lugar a una falta de integración. Esta imagen grandiosa de sí mismo es necesaria para prevenir el contacto con una vulnerabilidad dolorosa en su interior. A medida que el niño crece, el precio que ha de pagar por la conexión es continuar siendo la perfecta encarnación de la imagen de los padres del «niño perfecto». El niño puede entonces hacer una proyección de sus padres en las personas en general y proceder como si la aceptación de otras personas dependiese de la perfección: «Tengo que ser perfecto para ser mínimamente bueno». Una suposición subyacente, no siempre consciente pero poderosamente presente en las creencias de la persona sobre las relaciones, indica lo siguiente: «Si las personas no están de acuerdo con mi sentido del yo tan positivo, ¡me están atacando!» $\mathrm{Al}$ entrar en la vida adulta, esta actitud fomentará mucha reactividad a las críticas de los demás (es decir, retroalimentación de que no son perfectos) y otras personas tenderán a percibir que están intentando convencer a todo el mundo de su perfección. Los demás, por supuesto, van a resentirse y alejarse, lo que a su vez activa los antiguos recuerdos de abandono e indiferencia del individuo narcisista (Shapiro, 2001). Esto vuelve a estimular su necesidad de ser percibido como perfecto a ojos de los demás (P. F. Kernberg et al., 2000). Postulamos que esta era, en la infancia, la única defensa disponible frente al abandono total.

\section{Presentaciones del narcisismo en el tratamiento}

La presentación superficial de un paciente con rasgos narcisistas no siempre representa el cuadro completo de toda la estructura de la personalidad del paciente. La presentación superficial muy a menudo es una armadura que cubre un yo extremadamente vulnerable. Un estado del yo tan vulnerable puede no estar, ni parcial ni completamente, disponible para el acceso consciente. Los nuevos criterios del Manual diagnóstico y estadístico de los trastornos mentales ( $5^{\text {a }}$ ed.; DSM-5; APA, 2013) intentan reflejar esta ambivalencia, explicando que una autovaloración exagerada puede estar inflada o desinflada, o vacilar entre ambos extremos. En otras palabras, los rasgos narcisistas, aunque dañan tanto al individuo como a los demás, no están presentes necesariamente en la conducta del individuo en todo momento y esto puede ser confuso para los pacientes, sus allegados y los terapeutas.

Gabbard (1989) señala que la descripción normal de un trastorno narcisista de la personalidad se centra en las cualidades "obvias» del narcisismo (grandiosidad, explotación, arrogancia, problemas interpersonales e ira), mientras que omite las características menos obvias y sutiles o «encubiertas» (sensible a la vergüenza, introvertido, vulnerable, inhibido y con tendencia a la ansiedad). Aunque muchas presentaciones narcisistas son solamente la cubierta de un yo vulnerable, se han de evitar las generalizaciones. Existe un grupo de pacientes con una patología narcisista grave que han disociado completa e intensamente todos sus recuerdos de abandono y maltrato y, en consecuencia, tienen pocas posibilidades de sentirse "mal» $\mathrm{O}$ "inferiores» $\mathrm{O}$ tienen una experiencia interna de vacío u oquedad. Por el contrario, pueden intentar utilizar la terapia como vehículo para manipular a sus allegados. Un terapeuta bien intencionado puede hacer demasiadas preguntas tendenciosas y percibir erróneamente un falso yo vulnerable y recuerdos traumáticos tempranos no existentes mientras fracasa a la hora de poner el suficiente énfasis en proteger a los demás, como a los miembros de la familia, que pueden estar en peligro (Mosquera, 2012). 
El «narcisista en el armario»

Otra posibilidad es que los rasgos narcisistas sólo se hagan evidentes después de algún tiempo en tratamiento. Masterson (1981) define al "narcisista en el armario» como un paciente que se presenta humilde, tímido, inhibido y/o ineficaz, sólo para revelar más adelante en terapia las fantasías más elaboradas de su identidad grandiosa.

\section{El «narcisista sin principios»}

En casos de malos tratos evidentes, que resultan en procedimientos legales, algunos pacientes con tendencias narcisistas son derivados a terapia. Otras veces, los traen los propios parientes (parejas, padres), que han sufrido las consecuencias de su carácter y les están obligando a recibir tratamiento. A menudo, no es la persona con personalidad narcisista la que viene como paciente. En cambio, él o ella viene como familiar «colaborador» de una persona que busca terapia por diversos síntomas, y muchos de esos síntomas pueden haber resultado de las exigencias y demandas egoístas de la persona.

En los casos de personas que son dañinas, que vulneran los derechos de los demás y que pueden describirse como individuos antisociales («narcisista sin principios», Millon, 1996), es muy probable que la terapia sea complicada. La conducta de un narcisista sin principios se caracteriza por un sentido arrogante de la propia valía, indiferencia ante el bienestar de los demás y modales sociales fraudulentos e intimidantes. Estos individuos son conscientes de que explotan a los demás y esperan reconocimiento y consideración especiales sin asumir responsabilidades recíprocas. Adolecen de una falta de sentido genuino de la culpa y tienen muy poca conciencia social. Mantienen sus relaciones siempre y cuando haya algo que ganar (Millon, 1996).

En algunos casos, disfrutan haciendo daño a los demás (Mosquera, 2007). Podemos pensar en esta gente como individuos que aprendieron temprano en la vida a evitar el apego porque este siempre iba asociado a dolor emocional. Son difíciles de tratar porque su defensa de devaluación está tan profundamente arraigada que se ha convertido en su identidad. En muchos casos, la intervención terapéutica más realista es que aprendan sobre las consecuencias negativas de su comportamiento o proteger a los demás de ellos.

\section{El «narcisista elitista»}

Algunas personas con personalidades narcisistas presentan un perfil más sutil, como el "narcisista elitista» (Millon, 1996), descrito originalmente por Reich
(1949) como "narcisista fálico». A veces parecen ser personas bien adaptadas, pero como hablan mucho de sí mismos, son propensos a las discrepancias entre lo que son y el retrato que hacen de sí mismos. A diferencia de muchos otros que son conscientes de esta disparidad, los «elitistas» están completamente convencidos de que son maravillosos. En lugar de hacer un esfuerzo por adquirir aptitudeds y talentos genuinos, hacen grandes esfuerxos para persuadir a los demás de que son especiales. Pueden quedarse estupefactos, desilusionados e incluso enfados cuando otros no les devuelven su exageradamente valorada autoimagen. Muchos son arribistas que tratan de cultivar su sentido de ser especiales y su beneficio personal asociándose a aquellos con auténticos logros y reconocimiento. En cualquier actividad que realizan, invierten su energía en anunciarse a sí mismos, inflando sus logros, sean verdaderos o falsos, e intentando que cualquier cosa que hayan hecho bien parezca impresionante y mejor de lo que realmente es (Millon, 1996). En estos casos, puede haber una historia importante de ostentación, de ser el centro de atención, de exagerar síntomas, de darse importancia y un deseo de ser diferente. Estos pacientes consideran que han de ser tratados de manera diferente porque son especiales. Bajo estas actitud, a menudo se encuentra la fragmentación de la verdadera identidad o una dificultad extrema de conexión emocional. Un ejemplo es un hombre de mediana edad que se sintió destrozado emocionalmente cuando su esposa, después de años de sentirse ignorada, criticada y humillada por su marido, le pidió el divorcio.

\section{El «narcisista victimizado»}

Autodefinirse como "víctima» puede funcionar como sustituto de una realidad más global y realista. La historia de dichas personas puede incluir negligencia emocional temprana y extensa, pero en su vida presente esperan que otras personas cubran sus necesidades y les den lo que nunca tuvieron. Muchas personalidades con rasgos narcisistas terminan construyendo una identidad alrededor de la idea de que «me ha pasado todo lo malo». Este tipo de razonamiento y forma de "ver la vida» (a través de un filtro especialmente negativo y muy autorreferencial) normalmente genera mucho sufrimiento y muchas dificultades de adaptación para la persona (Mosquera, 2008). La sensación de la persona de haber sido una víctima es, en cierto modo, cierta en cuanto al maltrato en la infancia, pero esta sensación de victimización se aplica erróneamente a muchas situaciones del presente, lo que resulta en respuestas negativas repetidas por parte de los 
demás. La pieza narcisista de esta presentación clínica es la sensación de "tener derecho a», de merecimiento: «Me han tratado mal en el pasado, con lo cual hoy merezco un tratamiento especial». De este modo, el patrón se repite; la identidad de la víctima lleva paradójicamente a una revictimización porque el paciente sólo puede continuar jugando este papel (que le es familiar y esencial para su supervivencia psicológica) a través de relaciones abusivas.

Una variante de este subtipo de personalidad es una persona que se aferra a una etiqueta diagnóstica como identidad sustituta. Esta es una autovaloración de «ser un caso difícil y especial». Por ejemplo, un profesor de 52 años pidió una cita comentando que la terapeuta iba a tener suerte de evaluarle porque él era el caso más grave que ella tendría ocasión de ver jamás en su vida. Esta actitud puede ser una «llamada de socorro», pero también puede ser una señal diagnóstica para el terapeuta de que el paciente tiene un fuerte sentido de merecimiento y la sensación de que sería injusto pedirle que se ajustase a unas expectativas normales de responsabilidad.

\section{Pacientes con un estilo «sí, pero ....»}

Algunos pacientes pueden presentarse con una aparente baja autoestima y depresión, que normalmente moviliza atención y cuidados de parte de los demás. Sin embargo, esta atención y cuidados nunca parecen ser suficientes; es como que necesitan «algo más», algo que no pueden encontrar y podría satisfacerles. Estas personas piden ayuda, exigen tratamiento y vienen a citas, pero presentan una gran ambivalencia hacia permitir que se les ayude y tienden a hacer lo opuesto a las propuestas que inicialmente parecen aceptar (Mosquera, 2008). A nivel comunicativo y pragmático, estas verbalizaciones negativas sobre sí mismos son un intento de suscitar comentarios de apoyo de los demás. En lo más profundo, sus creencias son del estilo: «Estoy por encima de los demás», «mis valores son superiores», «la injusticia proviene del mundo y soy una víctima que no lo merece». Suelen atribuir sus problemas a algo externo y presentan grandes dificultades para asumir sus responsabilidades o centrarse en lo que depende de ellos. En ocasiones presentan un estilo pasivo-agresivo, haciendo que los demás hagan cosas por ellos, para finalmente lograr que esas personas se sientan ineficaces porque nada es suficientemente bueno nunca.

\section{El cuidador incansable o «narcisista complaciente»}

Algunos pacientes están centrados en lograr la aprobación de los demás y son muy vulnerables a las críticas.
Todas sus conductas están diseñadas para mostrar a los demás una imagen de "persona extremadamente buena»; parecen vivir "para» los demás y no entienden porque los demás no les «retribuyen». Aunque parecen "disfrutar» complaciendo a los demás, esperan algo a cambio pero tienen dificultades para reconocer esto y sienten resentimiento y rabia cuando los elegidos no responden como esperaban. Pueden construir una elaborada fachada de «bondad» y se sienten confusos cuando se encuentran con reacciones negativas por parte de los demás (Mosquera, 2008). Puede haber un cierto tipo de grandiosidad en su asunción de responsabilidad por las emociones y conductas de todo el mundo que les rodea. Este tipo de individuo puede sufrir una «herida narcisista», y/o sentir rabia e indignación, cuando otros no responden como esperaba a su bondad. Este subtipo puede ser una fuente de traumatización para sus hijos, quienes a menudo les describirán en la edad adulta como "padres maravillosos", aunque es posible que se sientan confusos y culpables por sentir resentimiento hasta estos padres sacrificados pero egocéntricos.

\section{Los retos del trabajo con EMDR con pacientes con narcisismo}

Para los terapeutas que tratan el narcisismo, puede ser complicado gestionar reacciones emocionales contratransferenciales negativas hacia aquellos pacientes que evitan de manera fóbica que el terapeuta importe y tienen una reacción visceral a culpar a los demás cuando se encuentran con frustraciones en la vida. Estos pacientes pueden decir cosas para poner a la defensiva al terapeuta, tales como: «¿Por qué estás tan seguro de que me puedes ayudar?» o, como dijo un paciente: «Mi principal problema es que el resto de la gente no actúa como debería. ¿iDe qué modo puede ayudarme EMDR con eso!?» El terapeuta podría comenzar una conversación sobre las diversas opciones a escoger cuando otras personas «no actúan correctamente« y el objetivo de la terapia puede ser decidirse por una de esas opciones (por ejemplo, aceptación o una conversación constructiva para solucionar problemas).

Es obvio que, inicialmente este patrón de personalidad puede impedir que el paciente se implique en un procesamiento eficiente de experiencias vitales traumáticas. La postura consciente, propuesta por Shapiro (2001) como prerrequisito para acceder a y procesar un recuerdo, no está presente normalmente en los trastornos de personalidad, donde las disrupciones tempranas del apego no permitieron un completo desarrollo de la integración entre los niveles de procesamiento cognitivo, emocional y sensoriomotor. 
En consecuencia, la persona desarrolló estructuras mentales defensivas para impedir el insoportable contacto con la perturbación y la vulnerabilidad (Afifi et al., 2011; Bennett, 2006).

\section{Activación de estructuras mentales defensivas}

Para el paciente con tendencias narcisistas, estas estructuras mentales defensivas tienden a activarse rápidamente y de forma automática en respuesta a cualquiera amenaza a su falsa identidad idealizada. En nuestra práctica, hemos visto que los pacientes con narcisismo tienen dificultades para ver de manera realista los problemas conflictivos con otras personas e identificar su propia contribución a dichos problemas. En su lugar, lo más probable es que culpen a los demás de forma rápida y casi automática, aparentemente para proteger su autoimagen idealizada.

\section{Narcisismo encubierto}

Una estructura narcisista de la personalidad puede ser muy obvia para muchas de las personas que observan a la persona con narcisismo, o estar encubierta y bien escondida excepto para aquellos que intentan tener una relación íntima con el individuo. ¿Cómo puede el terapeuta detectar el narcisismo encubierto? Los rasgos narcisistas obvios pueden identificarse fácilmente, pero las cuadros encubiertos son más difíciles. Normalmente, una estructura de personalidad narcisista escondida se volverá evidente en la reacción excesiva a una crítica o a un fallo que es, en sentido objetivo, menor. Los pacientes narcisistas no detectados pueden intentar (porque es algo normal para su patrón de funcionamiento) atraer la atención y admiración del terapeuta jugando el papel que creen va a preferir el clínico. Además, pueden presentar problemas y recuerdos de fácil solución para solidificar la conexión con el terapeuta.

\section{Identificación proyectiva}

El terapeuta que trabaja con pacientes con características narcisistas debería ser consciente de cierto tipo de identificación proyectiva, en la que el paciente idealiza al terapeuta y este después adopta la proyección de idealización del paciente y comienza a representarla como contratransferencia. El sentimiento del paciente en estas sesiones sería de «soy una persona especial y superior y tú eres mi terapeuta especial y superior». Esto puede ser una estratagema para que fracase la terapia si el terapeuta se implica en esta imagen idealizada de sí mismo o, si el paciente, por esta idealización mutua, rehúsa revelar fallos personales. Este patrón de identificación proyectiva puede también haber ocurrido en muchas de las otras relaciones del paciente. Para el paciente con narcisismo, los «10 eventos más perturbadores» pueden ser situaciones en las que los demás no reflejaron el self idealizado del paciente o situaciones en las cuales lo ideal no era alcanzable, donde ocurrió algo que reveló que el paciente no era tan superior.

\section{Tratamiento de larga duración}

Dada la complejidad de las personalidades narcisistas, normalmente será necesario un largo proceso para desmantelar la estructura de personalidad disfuncional (Mosquera, 2012). El terapeuta debe acompañar este desmantelamiento con un gran nivel de sintonía y atención hacia la seguridad emocional del paciente. Con frecuencia, enseñamos a nuestros pacientes con narcisismo a aceptar la realidad de una auténtica sintonía con otra persona, algo de lo que el paciente no recibió lo suficiente durante su infancia. El proceso de terapia a menudo es necesariamente lento porque, bajo el exterior narcisista, puede haber una reactividad y vulnerabilidad extremas hacia sentirse abandonado o sentirse atacado o humillado injustamente.

\section{¿Cuándo o por qué vienen a terapia los individuos con narcisismo?}

Las personas con cualidades narcisistas pueden ser tremendamente infelices en su vida, pero a menudo son reticentes a entrar en psicoterapia. Pueden temer estar en una situación de evaluación en relación a otra persona, revelar información personal que puede diferir de su autoimagen idealizada o estar en situaciones en las que la norma sea decir la verdad sin censura. Los pacientes con narcisismo, por sus características específicas de personalidad, normalmente no llegan a terapia con una buena comprensión de sus problemas o de los orígenes de sus problemas. Lo que suele ocurrir es que vienen a terapia acompañados por aquellos que sufren las consecuencias de sus actitudes y conductas egocéntricas, como se ha comentado anteriormente. Pueden solicitar ayuda profesional por los siguientes motivos:

- Falta de reflejo (mirroring) de los demás (los demás no les devuelven la imagen de sí mismos como ellos esperan)

- Problemas de pareja o intimidad

- Problemas laborales (normalmente con compañeros o superiores)

- Como familiares de un paciente identificado, que está sufriendo su egoísmo narcisista, su explotación o su falta de empatía; a veces incluso «mandan» a sus cónyuges o familiares a terapia para que los puedan mejorar o «arreglar». 
Muchos pacientes con estas características narcisistas sólo recurrirán a ayuda profesional después de haber tenido un choque con la realidad (Mosquera, 2012), lo que en ocasiones genera depresión. Esto normalmente ocurre cuando aparece alguien que hace que la imagen idealizada sea insostenible; algo «revienta la burbuja»: una herida narcisista (Knipe, 1998).

\section{Terapia EMDR para pacientes con narcisismo}

En el abordaje psicoterapéutico de EMDR, se considera que los problemas psicológicos están causados principalmente por un efecto acumulativo de experiencias traumáticas y adversas no resueltas (Shapiro, 2001, 2007). La terapia EMDR ha demostrado ser un tratamiento eficaz, eficiente y bien tolerado para el trastorno de estrés postraumático (TEPT; Bisson y Andrew, 2007; Foa, Keane, Friedman y Cohen, 2009; Ursano et al., 2004) y es eficaz para el TEPT con inicio tanto en la edad adulta como en la infancia (AdlerTapia y Settle, 2009; Field y Cottrell, 2011; Korn, 2009; van der Kolk et al., 2007).

En la terapia EMDR, se dirige al paciente a que note, en conciencia plena, lo que ocurre con las representaciones de imágenes visuales perturbadoras y disfuncionales, pensamientos negativos autorreferenciales, emociones, sensaciones, impulsos de acción y afirmaciones sobre sí mismo mientras presta atención a una serie de tandas de estimulación bilateral (EBL) que implican movimientos oculares, golpecitos o tonos auditivos alternados (Leeds, 2009; Shapiro, 2001). EMDR utiliza un abordaje de ocho fases y trata recuerdos pasados, disparadores presentes y situaciones futuras. Para evaluar los cambios durante el procesamiento, se utilizan dos escalas: la escala de unidades subjetivas de perturbación (SUD) y la escala de validez de la cognición (VOC).

En las dos primeras fases, el terapeuta recoge la historia del paciente, desarrolla la alianza terapéutica y prepara al paciente para la fase de reprocesamiento. Las fases 3 a 7 se centran en el reprocesamiento de un recuerdo diana. En la fase 3, el paciente identifica una imagen representativa para la diana, autoafirmaciones negativas y positivas relacionadas, emociones y sensaciones físicas. El paciente puntúa la validez de la cognición positiva (VOC: $1=$ no se siente cierta, $7=$ totalmente cierta) y la perturbación subjetiva de la emoción (SUD: 0 = ninguna perturbación, $10=$ peor perturbación posible). Durante la fase 4, el paciente nota como cambian los elementos mientras presta atención a la EBL alternante (generalmente movimientos de los ojos). La fase 4 termina cuando el nivel de perturbación (SUD) llega a 0 . En la fase 5 , se aplica EBL para reforzar la conexión entre la experiencia y la afirmación positiva hasta que la VOC llega a 7. En la fase 6 , el paciente indica cualquier sensación residual que necesita ser reprocesada. En la fase 7, el terapeuta se asegura de que el paciente alcance un punto de cierre. Se pide al paciente que tome notas internas y entienda estas experiencias como parte del proceso. En la fase 8, el terapeuta reevalúa los efectos de reprocesamiento y supervisa el progreso del paciente.

Realizar los procedimientos de EMDR puede ser todo un reto cuando se trabaja con estructuras complejas de personalidad, caracterizadas por patrones de defensa rígidos y estados del yo separados. Las partes de la personalidad pueden funcionar de forma muy separada y no tener acceso consciente y completo a las demás y también pueden tener problemas para «darse cuenta» del todo (van der Hart et al., 2006) de que el presente es diferente y está separado del pasado. Este fracaso a la hora de darse cuenta puede generar que sea más probable hacer proyecciones erróneas sobre los demás y esto puede causar problemas importantes en la relaciones, incluida la relación con un terapeuta. El terapeuta debe prestar atención a estas distorsiones porque tienen lugar dentro de la relación terapéutica.

\section{El plan terapéutico: selección y secuenciación de blancos}

Objetivo del tratamiento. Invertir mucha energía en una imagen exageradamente positiva de uno mismo puede dominar el sentido del yo de la persona, o puede simplemente ser un estado mental que aparece, en distintos grados, en ciertas circunstancias específicas. Tanto si la inversión es grande o pequeña, puede haber un cambio gradual en terapia de una inversión emocional en el "falso yo» a estar cómodo simplemente siendo el «yo real». Se renuncia al espejismo y hay un intercambio por esta pérdida: un aumento de la sensación de estar arraigado y tener coherencia dentro de uno mismo, así como una apertura a conexiones reales con otras personas. La persona puede llegar a aceptar: «No soy maravillosa, y eso está bien, y es un alivio saber que no soy terrible. Está bien ser simplemente quién soy». Es gratificante para la persona descubrir que tiene simplemente permiso para ser humano y ser consciente de la humanidad de los demás. La terapia con estos pacientes es, por necesidad, lenta y gradual.

Blancos o dianas iniciales. Masterson (1981) recomienda comenzar el tratamiento de una persona con rasgos narcisistas «reflejando la vulnerabilidad narcisista». En otras palabras, la construcción de la relación inicial tiene lugar a medida que el terapeuta 
empáticamente refleja la perturbación del paciente asociada con esos momentos en los que el falso yo no fue respaldado por los demás o, de algún modo, se reveló como egoísta, poco realista, vergonzoso o inadecuado. Por ejemplo, el terapeuta puede decir: «Puedo ver que, cuando ocurrió eso, fue muy desagradable. ¿Me puedes contar más sobre lo que estabas sintiendo en reacción a aquello?» De acuerdo con este abordaje, un terapeuta EMDR puede sugerir comenzar a hacer blanco con los acontecimientos que contienen una perturbación más accesible y aquellos que el paciente puede identificar fácilmente como negativos y problemáticos a nivel personal, tales como disparadores actuales o acontecimientos recientes. Una herida narcisista reciente (es decir, un suceso que minó gravemente el falso yo exageradamente positivo y distorsionado del paciente) puede ser un blanco muy accesible, uno que contenga sentimientos de humillación, rabia indefensa u otra emoción negativa. Esta situación puede proporcionar una buena oportunidad para presentar al paciente los procedimientos del procesamiento con EMDR y explicar los beneficios de este abordaje terapéutico. En la presentación inicial de la persona con rasgos narcisistas hay normalmente disponibles muchas situaciones de este estilo, porque el egocentrismo poco realista, la autocomplacencia y el sentido de merecimiento tienden a invitar respuestas negativas de los demás. La autoidealización poco realista, que ocurre en mayor o menor medida, con el tiempo probablemente resultará en humillación: un «choque con la realidad».

Hacer blanco sobre la primera, la peor y la más reciente herida narcisista. Si el paciente confía suficientemente en el terapeuta, se pueden revelar y comentar este tipo de situaciones dolorosas y, si es posible, se pueden identificar el primer, el peor y el más reciente ejemplo del tipo concreto de herida narcisista. Estas situaciones de heridas narcisistas pueden no acceder directamente a las experiencias centrales de la infancia temprana, pero con toda probabilidad serán accesibles más fácilmente con seguridad emocional y menor desafío a la estabilidad de la relación terapéutica. Debido a que se accede a y se procesan con éxito varias de estas situaciones a lo largo de un periodo de tiempo, la alianza terapéutica se verá fortalecida, lo cual da lugar, en última instancia, a que el paciente sea capaz de trabajar directamente con experiencias infantiles centrales de falta de implicación de los padres, abandono emocional y/o abuso.

Para algunos pacientes, es útil presentar este trabajo como un procedimiento de "alivio del estrés». Por ejemplo, los pacientes pueden venir a terapia quejándose de que otra persona no "actuó correctamente» y esto le estresó. El terapeuta puede decir: «Esto puede ayudar a que esta situación no te moleste tanto, aunque puede que no te quite todo el estrés que estás sintiendo».

A medida que el estrés de estas heridas de narcisismo va disminuyendo y el paciente es capaz de recordar estas situaciones con más claridad y menos perturbación, puede darse un cambio sutil pero importante: un cambio que les lleva a centrarse menos en las necesidades propias, en la sensación propia de merecimiento, a ver a los demás no tanto como objetos, sino como personas reales y separadas. La empatía -el interés y la implicación hacia las necesidades y experiencias independientes de los demás- puede presentarse al paciente como solución a un problema previamente confuso: «¿Por qué otras personas no responden de manera positiva hacia mí cuando soy tan impresionante?»

Poco a poco, el paciente con rasgos narcisistas puede llegar a ver, y sentir, la importancia de la empatía hacia los demás y que esta es la clave para relacionarse bien y con éxito con otras personas. A medida que esto va ocurriendo, el paciente también puede experimentar un cambio en la definición misma del yo, hacía una autopercepción más realista y equilibrada. Un paciente dijo: "Ahora puedo ver que no soy tan bueno, iy no soy tan malo!»

Hacer blanco sobre acontecimientos positivos iniciales que generaron autoidealización. Una vez que el paciente sea capaz de comenzar a tener este tipo de conocimiento sentido, puede empezarse a abrir la puerta para volver atrás y hacer blanco específicamente sobre los acontecimientos positivos que crearon la autoidealización en un primer momento, esto es, hacer blanco específicamente sobre el afecto positivo asociado a esos acontecimientos. Ejemplos de esto pueden ser recuerdos de ser mimado por uno de los padres, situaciones del presente en las que el individuo satisfizo una necesidad obsesiva de ganarse la admiración de los padres en el mundo de hoy en día o un momento en el que el paciente fue capaz de ganarse la admiración de otras personas. Normalmente, a medida que se va haciendo blanco sobre estos incidentes, el propósito defensivo de la autoidealización se hará cada vez más claro; esto es, el autoconcepto exageradamente positivo fue una manera de alejarse de, o de no sentir, el dolor emocional de acontecimientos traumáticos o de abandono. Por otro lado, puede ser útil identificar y hacer blanco sobre momentos en el pasado en los que hubo una herida narcisista -ocurrió algo que hizo que el autoconcepto narcisista fuese 
insostenible- y la persona se sintió humillada o desgraciada al menos por un corto periodo de tiempo hasta que se restableció el autoconcepto de perfección. Todos estos son ejemplos de hacer blanco sobre recuerdos con afecto positivo almacenados de manera disfuncional, recuerdos que forman las bases de las defensas de idealización que impiden el acceso total a los recuerdos con balance negativo de abuso o falta de implicación parental. Por lo general, sólo después de trabajar con varios ejemplos de cómo comenzaron las defensas de idealización, cuando ya exista una alianza fuerte y el paciente haya tenido una sensación de dominio en el trabajo con recuerdos desagradables, podemos proceder con el reprocesamiento del trauma de los recuerdos centrales (Mosquera, 2012).

Plantillas de futuro. Deben usarse plantillas de futuro para completar el abordaje de tres vertientes y solidificar los resultados conseguidos después del procesamiento de recuerdos pasados y disparadores presentes.

\section{Fase 1 en terapia EMDR con individuos con narcisismo: Recogida de historia}

Durante la fase 1, será especialmente necesario establecer una fuerte conexión terapéutica a través de un repetido entendimiento empático y certero por parte del terapeuta. Queremos que el paciente tenga un sentido claro de: «iMi terapeuta realmente lo entiende! ¡Mi terapeuta entiende quien soy!» El papel del terapeuta es ayudar al paciente con narcisismo a desarrollar curiosidad acerca de por qué los demás reaccionan a menudo negativamente y de esta manera empezar a vislumbrar que su inflado autoconcepto es poco realista y contraproducente. Es importante, al hablar de las ideas del paciente de superioridad y merecimiento, que el terapeuta use palabras que sean sensibles a las defensas subyacentes de vulnerabilidad y autoidealización del paciente, a fin de garantizar que no surjan sentimientos de vergüenza o ataque (Mosquera, 2012 ). El falso yo del paciente, con su sentido de superioridad y de merecimiento (Winnicott, 1965), pese a que parece fuerte y robusto, es normalmente muy frágil, una delgada capa que cubre sentimientos de vacío y, a menudo, dudas enormes sobre sí mismo. El paciente puede ser "grosero" y no mostrar mucha conciencia de las implicaciones ofensivas de algo que dice o los efectos de una determinada declaración. En las sesiones iniciales, es probable que sea mejor para el terapeuta evitar responder a estas groserías con interpretaciones prematuras. En algunos casos, incluso los ataques verbales contra el terapeuta pueden requerir una respuesta mínima; estos ataques pueden ser una "prueba», con una motivación no consciente, de si el terapeuta es capaz de mantener su autoestima (es decir, el paciente tiene que saber que el terapeuta tiene un sentido suficientemente resiliente de sí mismo) frente a los ataques. El paciente puede sorprenderse terapéuticamente por esta capacidad de resiliencia en el terapeuta, resiliencia que puede contrastar intensamente con la airada respuesta que el paciente haya recibido previamente de otras personas.

Los pacientes no podrán beneficiarse de la terapia si abandonan, por lo que los terapeutas deben estar atentos a los peligros de confrontar comportamiento problemáticos («acting out») demasiado pronto. Es necesaria la presencia de una mínima relación terapéutica positiva para que la confrontación sea eficaz y, cuanto mayor sea la confrontación, más fuerte tendrá que ser la relación. Una vez que el paciente sepa que el terapeuta está «de mi lado» y trabaja en beneficio del paciente, entonces la confrontación, ofrecida con compasión y empatía, será más eficaz. En otras palabras, el terapeuta debe tener cuidado de no confrontar el material del paciente en las primeras sesiones, independientemente de lo egoísta que pueda parecer (a menos que, por supuesto, el comportamiento del paciente esté a punto de causar algo muy perjudicial). Las primeras sesiones pueden estar llenas de defensas y esto puede continuar durante muchas sesiones porque el paciente tiene que demostrarse a sí mismo, una y otra vez, que el terapeuta no tomará represalias en la forma en que lo han hecho muchas otras personas en su vida. Esto no significa que el terapeuta deba ser falso, simplemente ha de estar muy en sintonía con el peligro de que el paciente realmente malinterprete la retroalimentación negativa. Paradójicamente, este enfoque puede hacer que entonces el paciente se encuentre cada vez más relajado y dispuesto a revelar aspectos potencialmente vulnerables de sí mismo.

\section{Fase 2 de la terapia EMDR: Preparación}

Durante la fase 2 de la terapia EMDR, el clínico debe evitar formular frases que impliquen que ve al paciente como necesitado de una estabilización prolongada, ya que esto podría conducir a la activación de las defensas e interferir con el tratamiento.

Intervenciones psicoeducativas. La fase de preparación será un largo y paciente proceso de desmantelar las muchas capas defensivas presentes en los pacientes que presentan rasgos narcisistas. La psicoeducación es a menudo muy útil para describir la manera en que pueden desarrollarse las defensas como adaptación a un entorno difícil en la infancia. Las defensas se explican como un intento de ayudarse a uno mismo, no 
un fallo o fracaso personal. Se pueden identificar los traumas tempranos, pero, dada la fragilidad de la estructura de la personalidad inicial del paciente, por lo general no será buena idea comenzar con los peores episodios o el reprocesamiento del trauma porque hay muchas muros que derribar antes de que podamos llegar a ese punto (Mosquera, 2012).

Antes de identificar los recuerdos relevantes almacenados disfuncionalmente que están alimentando la estructura narcisista, se necesita psicoeducación y reflexión en colaboración, junto con la reformulación de los problemas del paciente y su historia. Después de este proceso psicoeducativo, los pacientes son capaces de pensar de modo muy diferente acerca de su situación. Veamos algunos ejemplos (Mosquera, 2008):

Pedro: Mis padres siempre me han tratado como un ser especial, yo creía que era único, superior . . . salir al mundo real fue muy traumático para mí. Me preguntaba por qué ellos (los otros) no se daban cuenta de lo maravilloso que era. Con el tiempo, me di cuenta de que era yo quien no encajaba y, si era tan especial, ¿por qué no funcionaban mis relaciones? ¿Por qué siempre tenía problemas con los demás? La actitud de prepotencia no me ayudó, pero no era consciente de ello y miraba a los demás por encima del hombro por no ser capaces de ver lo que valía ... Estaba tan equivocado ... Nunca pensé en la posibilidad de que mi actitud pudiera estar influyendo en todo lo demás, yo creía que la gente debía tratarme de manera especial sólo porque era yo, qué vergüenza ... (p. 8)

Susana: Ahora, con distancia, creo que mis padres me han querido mucho, pero me han perjudicado terriblemente. No lo digo con resentimiento, como solía hacerlo, sino como algo que es real, algo que no han sido capaces de ofrecerme en mi educación, principios básicos de la relación con los demás, la importancia de tener en cuenta a los demás y lo enriquecedor que puede ser conocer otros puntos de vista. Yo nunca había pensado en esto antes. (p. 8)

Juan: Siempre he sentido desprecio hacia los demás, sus intereses, sus opiniones, sus criterios ... siempre pensando que no estaban a mi nivel de conversación ... qué absurdo . . . He pasado años alimentando la rabia y la sensación de injusticia, buscando cada detalle que pudiera justificar mi posición . . . siempre comparándome con los demás. Siento que he perdido muchas oportunidades a lo largo del camino . . nada era lo suficientemente bueno para mí, cualquier trabajo parecía "demasiado poco» para mí . . . si no era demasiado poco dinero, era muy poco rango, si no era esto, eran los compañeros de trabajo y jefes que eran incompetentes y si no, era que no me valoraban o no me trataban como «yo merecía». He dejado pasar muchas oportunidades, pero la diferencia es que ahora siento que he perdido esas oportunidades, no que «me las han quitado» o que me han saboteado ... Solía pensar que el problema era de los demás, ahora soy consciente de que el problema era yo ... ( p. 8 )

La introducción de estimulación bilateral en fase dos para pacientes con narcisismo. En la fase dos, puede utilizarse EBL para mejorar las intervenciones y procesar blancos no traumáticos, como defensas o problemas relacionales. El problema principal en este punto es no dejarse guiar erróneamente por la apariencia de seguridad, estabilidad y control del paciente y sobreestimar su resiliencia. La fragilidad escondida puede ser muy alta y el paciente puede desmantelarse si se procesan defensas que aún son necesarias para mantener una sensación de estabilidad y control.

Estrategias de estabilización. Los pacientes que presentan rasgos narcisistas necesitan aprender a desarrollar habilidades para la regulación de emociones o las relaciones interpersonales. Esta información debe introducirse con cuidado, ya que pueden ser hipersensibles a los mensajes que pueden sugerir que no son superiores, capaces o hábiles en todo. Puede ser necesario trabajar en la autodiferenciación como en otros trastornos de la personalidad (Mosquera, 2012; Mosquera y Gonzalez, 2014).

Incluso las intervenciones que suele ser estabilizadoras, tales como la instalación de recursos (Leeds, 2009) o trabajar con patrones de autocuidado (González y Mosquera, 2012; Mosquera y González, 2014), no deben utilizarse hasta que el paciente sea capaz de hacer progresos en cuanto a pensamiento reflexivo y llegar a tener un sentido más realista de sí mismo. Cuando el paciente mejora en su evaluación objetiva y certera de sus problemas, se pueden instalar recursos saludables y pautas de autocuidado.

El trabajo con recuerdos positivos idealizados. El trabajo con defensas (Knipe, 1998, 2005, 2014) que hace blanco sobre recuerdos con afecto positivo relacionados con el falso yo puede ser útil para un paciente que ha tomado conciencia de la naturaleza autodestructiva de la distorsionada idealización de sí mismo. Por ejemplo, un paciente de 31 años, estaba angustiado porque su novia, con la que vivía, no estaba suficientemente impresionada por sus altos ingresos. En ocasiones, se sentía confundido por comentarios de que a ella realmente no le importaba su 
nivel de ingresos y, en otros momentos, interpretaba los comentarios en el sentido de que ella no lo amaba. Fue muy útil para él volver a recuerdos muy concretos de cómo sus padres le habían dado el mensaje de que el poder adquisitivo era igual a valía personal. Este mensaje se había dado en un contexto de falta de implicación de los padres con él e incluso críticas intensas en otros momentos. Así que había aprendido: «La manera de estar conectado a otra persona es ganar mucho dinero y que luego te consideren valioso. $\mathrm{Si}$ no se reconoce mi poder adquisitivo, significa que a la otra persona le soy indiferente». Fue muy útil para él hacer blanco sobre el sentimiento positivo asociado con un recuerdo de un momento concreto cuando le había hablado a sus padres sobre su buen sueldo. $\mathrm{El}$ afecto positivo de este recuerdo, en un principio un «10» (en una escala de 0 a 10), disminuyó con tandas repetidas de EBL y esto vino acompañado de muchas imágenes de soledad en la infancia. Cuando se hizo blanco sobre ellas, usando las fases 3 a 7 de EMDR, este hombre llegó a un estado de resolución y a una nueva apreciación por el amoroso mensaje de aceptación que su novia había estado tratando de transmitirle. Este enfoque (llamado el nivel de afecto positivo [LOPA]; Knipe, 1998, 2014) debe utilizarse con estos pacientes sólo después de que se haya establecido una relación terapéutica suficientemente fuerte, ya que implica un alto nivel de autorrevelación por parte del paciente. Un terapeuta experimentado podría pensar: «Es esta una buena idea . . . reducir la fuerza de una defensa psicológica? ¿No dejará al paciente aún más vulnerable a recuerdos y sentimientos postraumáticos perturbadores?» Hemos visto que, por lo general, este no es el caso. Cuando se hace blanco sobre los orígenes del falso yo idealizado del paciente, en el contexto de una relación terapéutica sólidamente establecida, tiende a disminuir la fuerza de la defensa narcisista, junto con una reducción paralela en la intensidad del material del recuerdo traumático subyacente. Por lo tanto, se puede hacer blanco sobre este material de forma segura utilizando procedimientos estándar de EMDR para los recuerdos problemáticos.

La idealización puede ser de uno mismo o de otros. Por ejemplo, una paciente estaba en peligro por su actitud idealizada sobre su relación con un novio problemático. A pesar de que él estaba en la cárcel por haber estado a punto de matarla, ella estaba en negación de la situación y se aferraba a los momentos idealizados que pasó con él. Al hacer blanco sobre el mejor momento idealizado, ella fue capaz de darse cuenta de la situación.

El trabajo con partes $y$ disociación. Si el entorno familiar ha sido extremadamente negligente, desimplicado y/o abusivo, pueden existir graves divisiones dentro de la estructura de la personalidad (Afifi et al., 2011; Bennett, 2006; Lyons-Ruth, Dutra, Schuder y Bianchi, 2006; Mosquera, 2012; van der Hart et al., 2006). Puede haber una separación amnésica entre el estado del yo positivo e idealizado y otros estados del yo que guardan recuerdos de abandono solitario o abuso.

Ver a los pacientes con narcicismo como si tuvieran diferentes estados del yo o partes (p.ej., un falso yo grandioso, un niño vulnerable, una parte protectora agresiva) puede ayudar al paciente a entender la estructura subyacente y planificar intervenciones. El paciente puede tener acceso consciente a estas partes, o a los recuerdos que activan estas partes, y si este es el caso, y el paciente es capaz de obtener la suficiente seguridad emocional con el terapeuta, se puede hacer blanco sobre estos recuerdos utilizando los procedimientos estándar de EMDR. Debe evaluarse la secuencia de blancos en función de la necesidad continuada del paciente de seguridad emocional y estabilidad, así como del contrato terapéutico. Pero si hay un trastorno disociativo comórbido-acompañado de una historia de apego desorganizado en la infancia y una separación disociativa entre partes de la personalidad- el curso del tratamiento habrá de ser guiado por un «abordaje más progresivo» y será necesario trabajar con fobias disociativas y el sistema interno de partes (Gonzalez y Mosquera, 2012; van der Hart, Groenendijk, Gonzalez, Mosquera y Solomon, 2013).

\section{Fase 3: Evaluación}

Durante la fase 3, pueden surgir diversos problemas específicos al trabajar con esta población. Parece que a los pacientes con un estilo narcisista no les gusta que les pidan que puntúen sus experiencias de forma numérica, del modo en que se hace con la VOC y el SUD, tal vez porque los números les obligan a mirar más de cerca su propia experiencia interna.

Los problemas de la fase 3 suelen estar relacionados con cogniciones. Al establecer inicialmente una diana, el terapeuta no debería forzar demasiado para obtener una cognición negativa autorreferencial (CN). Puede ser útil permitirle al paciente expresar una $\mathrm{CN}$ sobre otras personas (o incluso pedirlo) antes de pedir una $\mathrm{CN}$ autorreferencial. También se pueden aceptar cogniciones como: «Todavía me molesta) (muy leve en comparación con otras $\mathrm{CN}$, pero una que la mayoría de las personas con narcisismo podrían aceptar) (Knipe, 1998). En este caso, la cognición positiva $(\mathrm{CP})$ puede ser algo igualmente leve: «Ya no me molesta». En cuanto a las CP, debemos 
tener cuidado de no aceptar una CP idealizada como "soy el mejor» o "soy superior», aun cuando es algo que el paciente pueda mencionar cuando se le pide la CP deseada (Mosquera, 2012). Un problema con el que nos encontramos es que las distintas partes de la personalidad pueden responder de manera diferente a las preguntas de la fase 3 . Una respuesta puede provenir de la parte del paciente que carga con la perturbación y otra respuesta puede provenir del falso yo idealizado. Por ejemplo, un paciente puede identificar un recuerdo perturbador y una $\mathrm{CN}$ acompañante de: «Eso realmente me molesta!» Después, el paciente puede decir que la CP asociada: «Eso no me molesta en absoluto» tiene una puntuación VOC de «isiete!»

\section{Fase 4: Desensibilización}

Los clinicos han de tener en cuenta que, de acuerdo con el modelo PAI, esperamos que las tandas de EBL ayuden a enlazar información adaptativa, pero esto no significa que estas asociaciones siempre se experimenten como algo positivo. Por ejemplo, un paciente con una defensa egocéntrica de culpar a los demás puede llegar a ser cada vez más consciente de su parte de culpa y de su responsabilidad en los acontecimientos difíciles. Por ejemplo, «soy culpable» es más adaptativo que "otros son la causa de mis problemas» en situaciones donde el paciente en realidad tiene parte de responsabilidad por lo que ha sucedido. El procesamiento puede parecer «un procesamiento invertido» que va de positivo (idealizado) a negativo (realista). Esta posibilidad muestra por qué es tan necesaria una alianza terapéutica sólida y de confianza en el trabajo con pacientes que tienen características narcisistas. Cuando la terapia avanza de manera útil y apropiada, el paciente está revelando necesariamente una enorme fragilidad y vulnerabilidad. El terapeuta debe tener cuidado de evitar palabras que posiblemente pudieran tener implicaciones de vergüenza, y la desvinculación del paciente de su falso yo idealizado debe proceder a un ritmo que este pueda tolerar.

A veces, puede que los terapeutas necesiten tomar una postura activa para garantizar que se incluyan todas las emociones en la fase de desensibilización. Por ejemplo, es posible que en la historia del paciente no se hayan permitido el miedo o la tristeza. Al paciente solo se le permitió ser un niño perfecto idealizado, sin los sentimientos o conductas que los padres no podían tolerar. El terapeuta puede introducir entretejidos como: «Permítete sentir TODOS tus sentimientos» o «déjalo salir, está bien».
Fase 5: Instalación

Algunos pacientes tienen problemas a la hora de buscar una $\mathrm{CP}$, ya que piensan erróneamente que necesitan estar convencidos de esta creencia antes de comenzar el reprocesamiento EMDR. A estos pacientes, el terapeuta puede decirles: «Yo no esperaría que tuvieras una puntuación alta (VOC) al comienzo de este trabajo. Si tu puntuación es un 1, 2 o 3, eso simplemente significa que el trabajo va bien encaminado".

En algunos casos, esta fase puede ser complicada porque los pacientes cuyos entornos tempranos han sido negligentes o traumáticos pueden carecer de redes positivas realistas con las que conectarse. Otros no tienen experiencias de afecto positivo compartido con sus cuidadores en la infancia y pueden sentir perturbación por las autoafirmaciones positivas debido a la falta de tolerancia al afecto positivo (Leeds, 2009). Estos pacientes pueden simplemente no estar familiarizados con las satisfacciones de relacionarse empáticamente con otras personas, bien porque estas experiencias no estaban en sus historias personales o, lo que es peor, porque se castigaba o ignoraba sistemáticamente la verdadera implicación o conexión con los demás.

Un importante "momento didáctico» se produce a menudo en la fase 5 , cuando el paciente se da cuenta de que una PC de superioridad o merecimiento no es realmente realista ni sostenible. En este punto, el terapeuta puede sugerir una PC más apropiada. Por ejemplo, en lugar de una PC a la defensiva: «Soy intocable / irrompible», el terapeuta puede sugerir una PC más realista: «Puedo protegerme».

\section{Fase 6: Escaneo corporal}

Dentro de la fase 6, parece que hay menos variaciones del protocolo habitual. Algunos pacientes con características narcisistas han aprendido a disociar ciertas sensaciones corporales y estas pueden ser más accesibles a la conciencia después de las fases anteriores de EMDR. Por ejemplo, después de las fases 4 y 5 , un paciente podría indicar más tensión física, cansancio o hambre (si la disociación del hambre era parte del falso yo inicial, como a veces ocurre con los pacientes anoréxicos). El terapeuta debe estar alerta ante la posibilidad de que estas sensaciones físicas puedan ser el comienzo de canales de información traumática adicionales y asegurarse de que el paciente es capaz de contener adecuadamente cualquier información emergente antes de salir de la sesión. 


\section{Fase 7: Cierre}

A menudo, es mejor dejar un blanco incompleto, y finalizar una sesión con un cierre adecuado y seguro, que forzar demasiado. Algunos blancos, tanto recuerdos de autoidealización como recuerdos de trauma/ negligencia, pueden requerir varias sesiones. Además de los procedimientos de cierre habituales, centrados en calmar las sensaciones de tensión, los autores también recomiendan preguntas tales como: «¿Qué has descubierto aquí hoy que te ayuda?» o «Al salir de aquí hoy, ¿qué quieres estar seguro de recordar, algo que te vaya a ser realmente útil?»

\section{Fase 8: Reevaluación}

Los pacientes que muestran inicialmente rasgos narcisistas pueden necesitar tiempo y sesiones adicionales para consolidar los nuevos conocimientos obtenidos durante las sesiones centradas en el procesamiento de recuerdos. Dentro de una sesión, los pacientes pueden ser capaces de desarrollar una comprensión clara de la forma en que la imagen excesivamente positiva e idealizada de sí mismos ha sido un problema en el logro de sus objetivos más amplios. Además, los pacientes pueden dejar de sentirse implicados emocionalmente con la necesidad de ser superiores o merecedores. Sin embargo, entre sesiones, pueden volver a relacionarse con los demás de manera defensiva y a la idealización del yo. Puede que sea necesario, a lo largo de muchas sesiones de terapia, identificar y seleccionar eventos adicionales que sentaron las bases iniciales de la autoidealización inapropiada. Puede haber recuerdos de atenciones excesivas a los 7 años, de rendir más que un hermano a los 9 años, de sentimientos de superioridad en relación a los compañeros de clase de la escuela secundaria, de ignorar los sentimientos de los demás en sus relaciones actuales o de trabajo, y así sucesivamente. A medida que va resolviendo cada uno de estos blancos de afecto positivo disfuncional, es probable que disminuya la implicación emocional de la persona con el falso yo narcisista. Mientras esto ocurre, también suele ser importante hacer que el paciente preste atención al aumento de satisfacción en cuanto a la relación con otras personas, relaciones empáticas sin el aspecto competitivo.

La fase de reevaluación es crucial para un reprocesamiento adecuado de las dianas. Es importante no perder el foco y evitar "saltar de blanco en blanco». El paciente puede traer diferentes aspectos para trabajar, pero es importante mantener el rumbo.

Algunos casos pueden evolucionar lentamente, especialmente los que nunca han estado en terapia antes, y por lo tanto no pueden, al principio, tener una identidad central real. Con el tiempo, a medida que eliminamos armaduras y capas de defensa, puede surgir un fuerte sentido de «iEste es quien realmente soy!»

Estos casos pueden necesitar un trabajo de reconstrucción tras las sesiones de procesamiento, en las que los pacientes aprenderán a mirarse por dentro, a reconocer lo que realmente son y a funcionar desde esta nueva perspectiva. En apariencia, los pacientes pueden empeorar durante esos momentos en los que entran en contacto con su yo real, sin estructuras defensivas, y todavía carecen de una identidad real. Durante esta parte de la terapia, cuando se están procesando ciertas cuestiones fundamentales, el trabajo con los patrones de autocuidado adquiere relevancia como referente para la reconstrucción de una nueva forma de relacionarse con el ser real. También es importante hacer desarrollo e instalación de recursos y/o reforzar los aspectos adaptativos y saludables de la personalidad (p. ej., relacionarse empáticamente con los demás). Es importante que el terapeuta se dé cuenta y aprecie los cambios positivos del paciente, y entretejer este reconocimiento positivo con la difícil tarea de renunciar a estas defensas tan arraigadas y hacer blanco directamente sobre los recuerdos perturbadores.

\section{Conclusión}

Los rasgos narcisistas pueden ser la consecuencia de un autoconcepto distorsionado y excesivamente idealizado, que a su vez ha surgido de muchas situaciones diferentes en la primera infancia, incluidas una adulación y sobreprotección excesivas. Además, este autoconcepto idealizado está relacionado con la necesidad de crear defensas psicológicas para evitar la aparición de recuerdos de abusos y abandono graves. Para que tenga lugar un proceso eficaz de terapia EMDR, es necesario entender el camino específico que ha recorrido cada paciente, desde sus experiencias tempranas concretas a sus verdaderos problemas actuales.

Un tratamiento eficaz del narcisismo implica resonar activamente con la autodefinición del paciente y la manera en la que el este percibe el problema que presenta; provocar la autoreflexión del paciente durante la fase de preparación; identificar las muchas posibles desviaciones y callejones sin salida de la terapia que pueden resultar de la sobreactivación de la defensa; identificar y tratar experiencias centrales de falta de conexión temprana, negligencia y trauma que pueden haber estado inicialmente encubiertas (es decir, bloqueadas de la conciencia) por las defensas; identificar 
y corregir empáticamente las distorsiones en la percepción que el paciente tiene sobre el terapeuta; y evitar reacciones contratransferenciales no terapéuticas que se activan en el terapeuta.

\section{Referencias}

Adler-Tapia, R., \& Settle, C. (2009). Evidence of the efficacy of EMDR with children and adolescents in individual psychotherapy: A review of the research published in peer-reviewed journals. Journal of EMDR Practice and Research, 3(4), 232-247.

Afifi, T. O., Mather, A., Boman, J., Fleisher, W., Enns, M. W., MacMillan, H., \& Sareen, J. (2011). Childhood adversity and personality disorders: Results from a nationally representative population-based study. Journal of Psychiatric Research, 45(6), 814-822.

American Psychiatric Association. (2013). Diagnostic and statistical manual of mental disorders (5th ed.). Arlington, VA: Author.

Battle, C. L., Shea, M. T., Johnson, D. M., Yen, S., Zlotnick, C., Zanarini, M. C., . . . Morey, L. C. (2004). Childhood maltreatment associated with adult personality disorders: Findings from the Collaborative Longitudinal Personality Disorders Study. Journal of Personality Disorders, 18, 193-211.

Bennett, S. (2006). Attachment theory and research applied to the conceptualization and treatment of pathological narcissism. Clinical Social Work Journal, 34(1), 45-60.

Bierer, L. M., Yehuda, R., Schmeidler, J., Mitropoulou, V., New, A. S., Silverman, J. M., \& Siever, L. J. (2003). Abuse and neglect in childhood: Relationship to personality disorder diagnoses. CNS Spectrum, 8, 737-754.

Bisson, J., \& Andrew, M. (2007). Psychological treatment of post-traumatic stress disorder (PTSD). Cochrane Database Systematic Review, (3), CD00338.

Cai, H., Kwan, V., \& Sedikides, C. (2012). A sociocultural approach to narcissism: The case of modern China. European Journal of Personality, 26, 529-535.

Campbell, W. K., \& Foster, C. A. (2002). Narcissism and commitment in romantic relationships: An investment model analysis. Personality and Social Psychology Bulletin, 28, 484-494.

Cohen, L. J., Tanis, T., Bhattacharjee, R., Nesci, C., Halmi, W., \& Galynker, I. (2014). Are there differential relationships between different types of childhood maltreatment and different types of adult personality pathology? Psychiatry Research, 215(1), 192-201.

Collishaw, S., Pickles, A., Messer, J., Rutter, M., Shearer, C., \& Maughan, B. (2007). Resilience to adult psychopathology following childhood maltreatment: Evidence from a community sample. Child Abuse and Neglect, 31, 211-229.

Cramer, P. (2010). Young adult narcissism: A 20 year longitudinal study of the contribution of parenting styles, preschool precursors of narcissism, and denial. Journal of Research in Personality, 45(1), 19-28.
DeWall, C. N., Pond, R. S., Campbell, W. K., \& Twenge, J. M. (2011). Tuning in to psychological change: Linguistic markers of psychological traits and emotions over time in popular U.S. song lyrics. Psychology of Aesthetics, Creativity, and the Arts, 5, 200-207.

Field, A., \& Cottrell, D. (2011). Eye movement desensitization and reprocessing as a therapeutic intervention for traumatized children and adolescents: A systematic review of the evidence for family therapists. Journal of Family Therapy, 33(4), 374-388.

Foa, E., Keane, T., Friedman, M., \& Cohen, J. (Eds.). (2009). Effective treatments for PTSD: Practice guidelines from the International Society for Traumatic Stress Studies. New York, NY: Guilford Press.

Foster, J. D., Campbell, W. K., \& Twenge, J. M. (2003). Individual differences in narcissism: Inflated self-views across the lifespan and around the world. Journal of Research in Personality, 37, 469-486.

Gabbard, G. (1989). Two subtypes of narcissistic personality disorder. Bulletin of the Menninger Clinic, 53, 527-532.

Gibb, B. E., Wheeler, R., Alloy, L. B., \& Abramson, L. Y. (2001). Emotional, physical, and sexual maltreatment in childhood versus adolescence and personality dysfunction in young adulthood. Journal of Personality Disorders, 15, 505-511.

Gonzalez, A., \& Mosquera, D. (2012). EMDR and dissociation. The progressive approach. Madrid, Spain: Ediciones Pléyades.

Grover, K. E., Carpenter, L. L., Price, L. H., Gagne, G. G., Mello, A. F., Mello, M. F., \& Tyrka, A. R. (2007). The relationship between childhood abuse and adult personality disorder symptoms. Journal of Personality Disorders, 21, 442-447.

Hamamura, T. (2012). Are cultures becoming individualistic? A cross-temporal comparison of individualismcollectivism in the United States and Japan. Personality and Social Psychology Review, 16, 3-24.

Johnson, D. M., Shehan, T. C., \& Chard, K. M. (2004). Personality disorders, coping strategies, and posttraumatic stress disorder in women with histories of childhood sexual abuse. Journal of Child Sexual Abuse, 12, 19-39.

Johnson, J. G., Cohen, P., Brown, J., Smailes, E. M., \& Bernstein, D. P. (1999). Childhood maltreatment increases risk for personality disorders during early adulthood. Archives of General Psychiatry, 56, 600-608.

Johnson, J. G., Cohen, P., Chen, H., Kasen, S., \& Brook, J. S. (2006). Parenting behaviors associated with risk for offspring personality disorder during adulthood. Archives of General Psychiatry, 63, 579-587.

Johnson, J. G., Smailes, E. M., Cohen, P., Brown, J., \& Bernstein, D. P. (2000). Association between four types of childhood neglect and personality disorder symptoms during adolescence and early adulthood: Findings of a community-based longitudinal study. Journal of Personality Disorders, 14, 171-187.

Jonason, P. K., Lyons, M., \& Bethell, E. (2014). The making of Darth Vader: Parent-child care and the Dark Triad. Personality and Individual Differences, 67(2014), 30-34. 
Kernberg, O. (1975). Borderline conditions and pathological narcissism. New York, NY: Aronson.

Kernberg, P. F. (1998). Developmental aspects of normal and pathological narcissism. En E. F. Ronningstam (Ed.), Disorders of narcissism: Diagnostic, clinical and empirical implications (pp. 103-120). Washington, DC: American Psychiatric Association.

Kernberg, P. F., Weiner, A. S., \& Bardenstein, K. K. (2000). Personality disorders in children and adolescents. New York, NY: Basic Books.

Knipe, J. (1998). It was a golden time: Healing narcissistic vulnerability. En P. Manfield (Ed.), Extending EMDR (pp. 232-255). New York, NY: Norton.

Knipe, J. (2005). Targeting positive affect to clear the pain of unrequited love: Codependence, avoidance and procrastination. En R. Shapiro (Ed.), EMDR solutions (pp. 189-211). New York, NY: Norton.

Knipe, J. (2007). Loving eyes: Procedures to therapeutically reverse dissociative processes while preserving emotional safety. En C. Forgash \& M. Copeley (Eds.), Healing the heart of trauma and dissociation (pp. 181-226). New York, NY: Springer Publishing.

Knipe, J. (2014). EMDR toolbox: Theory and treatment for complex PTSD and dissociation. New York, NY: Springer Publishing.

Kohut, H. (1971). The analysis of the self: A systematic approach to the psychoanalytic treatment of narcissistic personality disorder. New York, NY: University of Chicago Press.

Konrath, S. H., O’Brien, E. H., \& Hsing, C. (2011). Changes in dispositional empathy in American college students over time: A meta-analysis. Personality and Social Psychology Review, 15, 180-198.

Korn, D. (2009). EMDR and the treatment of complex PTSD: A review. Journal of EMDR Practice and Research, 3(4), 264-278.

Kowalski, R. M. (2001). Behaving badly: Aversive behaviors in interpersonal relationships. Washington, DC: American Psychological Association.

Leeds, A. M. (2009). A guide to the standard EMDR protocols for clinicians, supervisors, and consultants. New York, NY: Springer Publishing.

Livesley, W. J., Jang, K. L., Jackson, D. N., \& Vernon, P. A. (1993). Genetic and environmental contributions to dimensions of personality disorder. American Journal of Psychiatry, 150(12), 1826-1831.

Lobbestael, J., Arntz, A., \& Berstein, D. P. (2010). Disentangling the relationship between different types of childhood maltreatment and personality disorders. Journal of Personality Disorders, 24, 285-295.

Luntz, B. K., \& Widom, C. (1994). Antisocial personality disorder in abused and neglected children grown up. The American Journal of Psychiatry, 151, 670-674.

Lyons, M., Morgan, K., Thomas, J., \& Al Hashmi, A. (2013). Patterns of parental warmth, attachment, and narcissism in young women in United Arab Emirates and the United Kingdom. Individual Differences Research, 11(4), 149-158.
Lyons-Ruth, K., Dutra, L., Schuder, M. R., \& Bianchi, I. (2006). From infant attachment disorganization to adult dissociation: Relational adaptations or traumatic experiences? Psychiatric Clinics of North America, 29(1), 63-viii.

Masterson, J. F. (1981) The narcissistic and borderline disorders. An integrated developmental approach. New York, NY: Routledge.

Millon, T. (1990). The disorders of personality. En L. A. Pervin (Ed.), Handbook of personality (pp. 339-370). New York, NY: Guilford Press.

Millon, T. (1996). Disorders of personality: DSM-IV and beyond (2nd ed.). New York, NY: Wiley.

Mosquera, D. (2007). Desmontando corazas. El trastorno antisocial aprendido: Un mecanismo de defensa extremo. [Removing shields: The antisocial learned: A defense mechanism end] Madrid, Spain: Ediciones Pléyades.

Mosquera, D. (2008). Personalidades narcisistas y personalidades con rasgos narcisistas. Revista Persona, 8(2). Buenos Aires, Argentina: Instituto Argentino para el Estudio de la Personalidad y sus Desórdenes.

Mosquera, D. (2012). Narcissistic personalities, trauma and EMDR. Trabajo presentado en el Congreso Nacional de EMDR, Holanda, Países Bajos.

Mosquera, D. (2013, June). Understanding and treating narcissistic personality disorder with EMDR. Trabajo presentado en la $14^{\mathrm{a}}$ Conferencia EMDR Europa, Ginebra, Suiza.

Mosquera, D., \& Gonzalez, A. (2011). Narcissism as a consequence of trauma and early experiences. ESTD Newsletter, 1(2), 4-6.

Mosquera, D., \& Gonzalez, A. (2014). Borderline personality disorder and EMDR therapy. Madrid, Spain: Ediciones Pléyades.

Nathanson, D. L. (1992). Shame and pride: Affect, sex, and the birth of the self. New York, NY: Norton.

Reich, W. (1949). Character analysis (3rd ed.). New York, NY: Farrar, Straus, \& Giroux.

Rettew, D. C., Zanarini, M. C., Yen, S., Grilo, C. M., Skodol, A. E., Shea T., . . G Gunderson, J. G. (2003). Childhood antecedents of avoidant personality disorder: A retrospective study. Journal of the American Academy of Child and Adolescent Psychiatry, 42, 1122-1130.

Segrin, C., Woszidlo, A., Givertz, M., \& Montgomery, N. (2013). Parent and child traits associated with overparenting. Journal of Social and Clinical Psychology, 32(6), 569-595.

Shapiro, F. (2001). Eye movement desensitization and reprocessing. Basic principles, protocols and procedures (2nd ed.). New York, NY: Guilford Press.

Shapiro, F. (Ed.). (2007). EMDR as an integrative psychotherapy approach (2nd ed.). Washington, DC: American Psychological Association.

Stone, M. H. (1993). Abnormalities of personality: Within and beyond the realm of treatment. New York, NY: Norton. Tartakoff, H. H. (1966). The normal personality in our culture and the Nobel Prize complex. En R. M. Loewenstein, L. M. Newman, M. Schur, \& A. J. Solint 
(Eds.), Psychoanalysis-A General psychology (pp. 222-252). New York, NY: International Universities Press.

Trzesniewski, K. H., Donnellan, M. B., \& Robins, R. W. (2008). Do today's young people really think they are so extraordinary? An examination of secular trends in narcissism and self-enhancement. Psychological Science, 19, 181-188.

Twenge, J. M., Campbell, W. K., \& Gentile, B. (2012). Increases in individualistic words and phrases in American books, 1960-2008. PLoS ONE, 7, e40181.

Twenge, J. M., Konrath, S., Foster, J. D., Campbell, W. K., \& Bushman, B. J. (2008). Egos inflating over time: A crosstemporal meta-analysis of the Narcissistic Personality Inventory. Journal of Personality, 76, 875-902.

Tyrka, A. R., Wyche, M. C., Kelly, M. M., Price, L. H., \& Carpenter, L. L. (2009). Childhood maltreatment and adult personality disorder symptoms: Influence of maltreatment type. Psychiatry Research, 165(3), 281-287.

Ursano, R. J., Bell, C., Eth, S., Friedman, M., Norwood, A., Pfefferbaum, B., . . . Yager, J. (2004). Practice guideline for the treatment of patients with acute stress disorder and posttraumatic stress disorder. American Journal of Psychiatry, 161(11), 3-31.

Van der Hart, O., Groenendijk, M., Gonzalez, A., Mosquera, D., \& Solomon, R. (2013). Dissociation of the personality and EMDR therapy in complex trauma-related disorders: Applications of the stabilization phase. Journal of EMDR Practice and research, 7(2), 81-94.

Van der Hart, O., Nijenhuis, E., \& Steele, K. (2006). The haunted self. Structural dissociation and the treatment of chronic traumatization. New York, NY: Norton.

Van der Kolk, B. A., Spinazzola, J., Blaustein, M. E., Hopper, J. W., Hopper, E. K., Korn, D. L., \& Simpson, W. B. (2007). A randomized clinical trial of eye movement desensitization and reprocessing (EMDR), fluoxetine, and pill placebo in the treatment of posttraumatic stress disorder: Treatment effects and long-term maintenance. Journal of Clinical Psychiatry, 68(1), 37-46.

Volkan, V. D. (1973). Transitional fantasies in the analysis of a narcissistic personality. Journal of the American Psychoanalytic Association, 21, 351-376.
Winnicott, D. W. (1965). Ego distortion in terms of true and false self. En The maturational processes and the facilitating environment (pp. 37-55). New York, NY: International Universities Press.

Yen, S., Shea, T., Battle, C. L., Johnson, D. M., Zlotnick, C., Dolan-Sewell, R., . . . McGlashan, T. H. (2002). Traumatic exposure and posttraumatic stress disorder in borderline, schizotypal, avoidant, and obsessive-compulsive personality disorders: Findings from the collaborative longitudinal personality disorders study. Journal of Nervous and Mental Disease, 190(8), 510-518.

Zanarini, M. C., Frankenburg, F. R., Reich, D. B., Marino, M. F., Lewis, R. E., Williams, A. A., \& Khera, G. S. (2000). Biparental failure in the childhood experiences of borderline patients. Journal of Personality Disorders, 14(3), 264-273.

Zanarini, M. C., Gunderson, J. G., Marino, M. F., Schwartz, E. O., \& Frankenburg, F. R. (1989). Childhood experiences of borderline patients. Comprehensive Psychiatry, 30(1), 18-25.

Zanarini, M. C., Williams, A. A., Lewis, R. E., Reich, R. B., Vera, S. C., Marino, M. F., . . F Frankenburg, F. R. (1997). Reported pathological childhood experiences associated with the development of borderline personality disorder. American Journal of Psychiatry, 154(8), 1101-1106.

Zanarini, M. C., Yong, L., Frankenburg, F. R., Hennen, J., Reich, D. B., Marino, M. F., \& Vujanovik, A. A. (2002). Severity of reported childhood sexual abuse and its relationship to severity of borderline psychopathology and psychosocial impairment among borderline inpatients. Journal of Nervous and Mental Disease, 190(6), 381-387.

La correspondencia relacionada con este artículo debe dirigirse a: Dolores Mosquera, INTRA-TP, Instituto para el Estudio del Trauma y los Trastornos de la Personalidad, General Sanjurjo 111, 5 , 15006, A Coruña, España. E-mail: doloresmosquera@gmail.com 